\section{Capturing the secrets of Nature}

Natural history must still be the subject most likely to kindle an interest in science in the tinder-dry mind of a young child. The problem is how to tend the flame so that the interest becomes a passion. When I was a child the process included Nature walks, listening to BBC radio's Nature Parliament and How Things Began and, of course, books. Now, streets ahead of anything else, there is film.

Film allows us and our children, at home and at school, to view every intimate detail of the erstwhile secrets of Nature. No longer do we wonder what goes on in the darkness of a woodpecker's nest nor contemplate the riddle of the landing of a fly on the ceiling. Given a steady diet of fantastic film, can the jading palate of today's child still be tempted by a book on Natural History? To judge by the masses of such books on the market the answer must be yes, or at least the adults who buy the books must believe so. For a book to be successful, however, it must surely attempt to match rather than ignore the dramatic qualities that the moving film has brought us. Only one of three series currently available really does that.

The success of the $A$ Closer Look At . . series (Hamish Hamilton: London, $£ 1.50$ each) rests heavily on the illustrations and the consistently good, sometimes inspired, layout. There are no photographs in these books. Instead the pages are generously supplied with full colour drawings which, at their best (for example, in . . Elephants and . . Apes) are vivid double-page spreads capturing a group of animals in mid-action. Each double page also has a few hundred words of text addressed to a particular topic, which vary from book to book but which generally start with evolution or geography and close with the prospects for... Information in the main part of the book is, however, centred either on species or behaviour. With such a limited amount of text the choice of topics or facts has inevitably been slightly arbritary but a certain balance has nevertheless been maintained in each volume.

The publishers of the series make no claim as to the age group for which it is suited. The books certainly succeed as picture books for the six year oldparticularly the more gory offerings, such as the death by leopard of an Australopithocine boy (...Prehistoric Mammals) or the spider-killing wasp ( . . Bees and Wasps) and I am sure that the text would carry the series up to the start of the teens. There are occasional oddities: the concept of

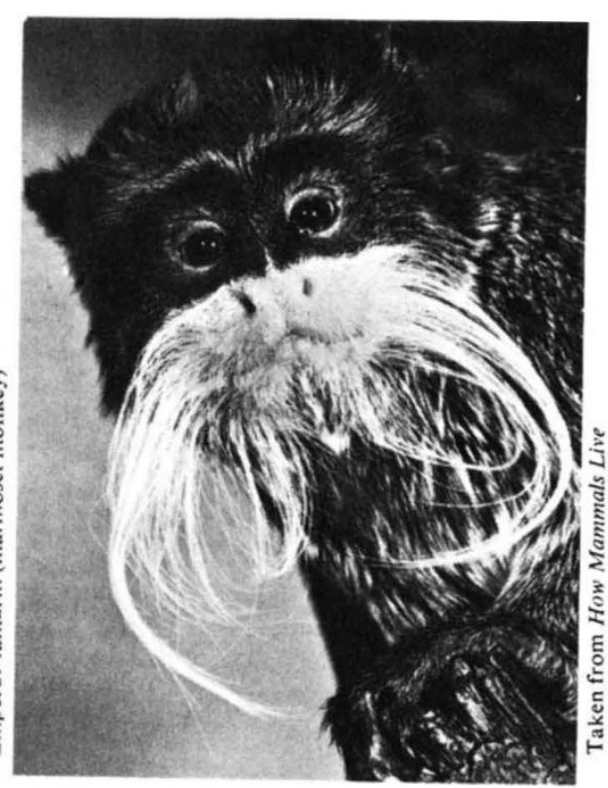

nidifigous and nidiculous birds may be worth a page in the ... Birds book but surely one could do without the terms themselves. And failings: the quality of the illustrations in . . A Arctic Lands. But overall these are excellent and reasonably priced books.

The second series, to which How Insects Live (Elsevier-Phaidon: Oxford, $£ 4.50$ ) is the latest addition, is clearly, if not explicitly, aimed at the teenager. But it would have to be an already committed one who actually benefited from the books. That, to my mind, is the failing of the series. In general design the volumes resemble a 'coffeetable' production both in size and in the abundance of handsome colour photographs. But the design belies the text which is by turns dull, didactic or of the "just-fancy-that" variety. Where

\section{Nature on the seashore}

Although books about the seashore might seem more relevant as a preparation for summer holidays, they may nevertheless make acceptable Christmas presents for scientists specialising in other subjects, laymen or the generation still at school or university. Two books have appeared in the shops during 1976 and it is interesting to compare them with some other books written over the last 27 years which are still available.

Taking the new books first, we have The Hamlyn Guide to the Seashore and Shallow Seas of Britain and Europe by A. C. Campbell (Hamlyn: London and New York, £2.25). This book is bound in durable paper that might withstand rain or seawater to a limited extent during shore collecting. The illustrations, by James Campbell, all in colour, are well above the average for this type of book. After a very brief exactly did the editor expect to find readers whose attention would be captured by Haeckel's dictum that "ontogeny repeats phylogeny" (How Fishes Live, £3.95) or by the correlation between the breeding behaviour of ring doves and the weights of their oviduct and crop contents (How Birds Live, £3.95)? Perhaps the bookish student, aged 15 or over, will appreciate these volumes; otherwise, buy them only if you cannot resist the photographs.

The Nature's Way series (G. Whizzard/André Deutsch: London, $£ 1.75$ each) is to my mind an even greater failure. The origin of this series is the Oxford Scientific Film Unit which is rightly renowned for its Natural History films. These books (Bees and Honey, Life and Times of the Stickleback, Butterfly Cycle) are clearly spinoff material. Each consists of about five pages of simple text followed by about twenty full page coloured photographs. The text is unexceptional, and the photographs are generally fine, but I was dissatisfied, perhaps through frustration, at the inevitable failure to translate action into stills photography. Once through these books was enough for me, and would, I suspect be enough for children. Not enough, however, to be able to recommend them as worth buying.

I have surprised myself by coming down heavily in favour of the series of books that relies on artistic rather than photographic illustrations. If you want the 'real' thing I can only say stick to television or, far better, head for the country.

Peter Newmark

Peter Newmark is Biological Manuscripts Editor of Nature.

introduction on types of seashore, tides and collecting, the non-biologist is thrown in at the deep end with two pages of "key" which cover the entire plant and animal kingdom. The reader must then find his or her way to the right phylum where a brief description of the phylum is followed by a list of species divided into classes and families. It is essential for the reader to find the plant or animal by its picture. Once this has been achieved the genus, species, authority, popular name, size, brief description, habitat and distribution are given. At the end of the book there is a glossary, bibliography and index. For identifying shore life, this book may well be the best available on the market and at its modest price is strongly recommended for the amateur shore collector.

The second new book, $A$ Field Guide to the Mediterranean Seashore by W. Luther and K. Fiedler, translated and edited by P. J. Miller (Collins: London, £4.95) is a hardback with a cover of what seems to be 